Clowes, R. C. \& Rowley, D. (1954). J. gen. Microbiol. 11, 250-260

\title{
Some Observations on Linkage Effects in Genetic Recombination in Escherichia coli K-12
}

\author{
By R. C. CLOWES AND D. ROWLEY \\ The Wright-Fleming Institute of Microbiology, St Mary's \\ Hospital Medical School, London, W. 2
}

SUMMARY: Further recombination data have been obtained from matings involving different $\mathrm{F}^{+}$auxotrophic mutants of Escherichia coli strain $\mathrm{K}-12$ with the same $\mathrm{K}-12 \mathrm{~F}^{-}$auxotroph. Variations in the distribution of sugar fermentation markers among the progeny have been explained by the influence of the 'contra-selected' $F^{+}$ auxotrophic marker. It is suggested that the data supports the conception of a single linear chromosome in $\mathrm{K}-12$, which fragments randomly during recombination.

Genetic investigation of inhibition of the K-12 strain of Escherichia coli by norleucine (Clowes \& Rowley, 1954) showed that the segregation of six sugar markers among progeny from the matings of the same $\left(\mathrm{T}^{-} \mathrm{L}^{-} \mathrm{B}_{1}^{-}\right) \mathrm{F}^{-}$strain with two different $\left(\mathbf{T}^{+} \mathbf{L}^{+} \mathbf{B}_{1}^{+}\right) \mathbf{F}^{+}$strains was comparable. This suggested that the same factors $\mathrm{T}^{+}, \mathrm{L}^{+}$, and $\mathrm{B}_{1}^{+}$were transferred from the $\mathrm{F}^{+}$to the $\mathrm{F}^{-}$parent in each case, accompanied by transfer of some unselected markers carried by the $\mathrm{F}^{+}$strain, in proportions depending only upon their proximity to the loci $\mathrm{T}^{+}, \mathrm{L}^{+}$and $\mathrm{B}_{1}^{+}$. This interpretation, based on the one-way transfer of genetic material proposed by Hayes (1952), suggests that the essential and uncomplicated function of the $\mathrm{F}^{+}$parent is to contribute that fragment of the bacterial chromosome (or chromosomes) needed by the $\mathrm{F}^{-}$parent to provide the complete genotype demanded by the selecting medium. However, further matings involving the same $\mathbf{F}^{-}$strain showed differences in the distributions of these sugar markers among the progeny when compared with similar data from the previous matings. That these differences are due to complications introduced by the relative positions of the selected markers of the $\mathrm{F}^{+}$parent with respect to those of the $\mathrm{F}^{-}$parent and to these sugar markers is shown in the following.

\section{MATERIALS AND METHODS}

Strains of Escherichia coli used

(a) Wild type Strain K-12. This strain grows on a minimal medium (Davis \& Mingioli, 1950) unsupplemented by amino acids or vitamins. It is sensitive to streptomycin and ferments maltose, lactose, D-galactose, D-xylose, D-mannitol and L-arabinose $\left(\mathrm{Mal}^{+}, \mathrm{Lac}^{+}, \mathrm{Gal}^{+}, \mathrm{Xyl}^{+}, \mathrm{Mtl}^{+}, \mathrm{Arab}^{+}\right)$. This strain crosses with $\mathrm{F}^{-}$strains and is thus $\mathrm{F}^{+}$.

(b) Strain 58-161. A methionine requiring mutant ( $\mathrm{M}^{-}$) of $\mathrm{K}-12$, having the same fermentation pattern $\left(\mathrm{Mal}^{-}, \mathrm{Lac}^{+}, \mathrm{Gal}^{+}, \mathrm{Xyl}^{+}, \mathrm{Mtl}^{+}, \mathrm{Arab}^{+}\right)$as the parent strain. Both $\mathrm{F}^{+}$and $\mathbf{F}^{-}$types were used.

(c) Strain W-677. A threonine, leucine and thiamine $\left(\mathrm{T}^{-}, \mathrm{L}^{-}, \mathrm{B}_{1}^{-}\right)$requiring auxotroph of K-12. This strain was derived from strain $\mathrm{W}-1\left(\mathrm{~T}^{-}, \mathrm{L}^{-}, \mathrm{B}_{1}^{-}\right.$, 
$\mathrm{Mal}_{1}^{-}, \mathrm{Lac}_{1}^{-}$) by incorporating the inability to ferment galactose, xylose, mannitol and arabinose in a series of separate steps, the $\mathrm{Gal}^{-}$locus being designated $\mathrm{Gal}_{5}^{-}$(E. M. Lederberg, personal communication). $\mathrm{F}^{+}$and $\mathbf{F}^{-}$ forms of this mutant were used together with the streptomycin-resistant mutant $\left(\mathrm{St}^{\mathrm{R}}\right)$ of the $\mathrm{F}^{-}$form $\left(\mathrm{W}-677 / \mathrm{St}^{\mathrm{R}} / \mathbf{F}^{-}\right)$. The genetic markers carried by W-677 are allelic with those of strain W-945, which has been the basis of other genetic investigations (Cavalli, Lederberg \& Lederberg, 1953), for the loci $T$, $\mathbf{L}, \mathbf{B}_{1}, \mathrm{Mal}$ and Lac since both strains are derived from $\mathrm{W}-1$. The St and $\mathrm{Xyl}$ loci have been assumed to be allelic and the allelism of the Xyl loci is supported by recombination data (L. L. Cavalli-Sforza, personal communication).

(d) The other auxotrophic strains of K-12 (designated ' $\mathrm{J}$ ' strains) used in this investigation are listed in Table 1.

Table 1. Derivation and requirements of ' $J$ ' strains of Escherichia coli

\begin{tabular}{|c|c|c|c|c|c|}
\hline Strain: & $\mathbf{J}_{4} \mathbf{5} \mathbf{5}^{*}$ & J5-3* & $\mathrm{J} 5-10^{*}$ & J 6-2* & J 13-4 \\
\hline Derivation: & $\begin{array}{l}\text { Double mu- } \\
\text { tant by ir- } \\
\text { radiation }\end{array}$ & \multicolumn{2}{|c|}{$\begin{array}{l}\text { From the same proline- } \\
\text { requiring mutant }\end{array}$} & From J 4-5 & From 58-161 \\
\hline $\begin{array}{l}\text { Require- } \\
\text { ments : } \dagger\end{array}$ & $\begin{array}{c}\text { Tryptophan, } \\
\text { Histidine } \\
\left(\mathbf{T} \bar{r}, \mathbf{H}^{-}\right)\end{array}$ & $\begin{array}{l}\text { Proline, } \\
\text { Methionine } \\
\left(\mathbf{P}^{-}, \mathbf{M}_{\mathbf{2}}^{-}\right)\end{array}$ & $\begin{array}{l}\text { Proline, } \\
\text { Histidine } \\
\left(\mathrm{P}^{-}, \mathbf{H}^{-}\right)\end{array}$ & $\begin{array}{l}\text { Proline, } \\
\text { Histidine, } \\
\text { Tryptophan } \\
\left(\mathbf{P}^{-}, \mathbf{H}^{-}, \mathbf{T} \overline{\mathbf{r}}\right)\end{array}$ & $\begin{array}{l}\text { Methionine, } \\
\text { Isoleucine or } \\
\alpha \text {-aminobuty- } \\
\text { ric acid }\left(\mathbf{M}_{1}^{-},\right. \\
\left.\text {iL }^{-} \text {or } \alpha-\mathrm{aB}^{-}\right)\end{array}$ \\
\hline
\end{tabular}

* Derived from K-12 passing through a Lac $^{-}$mutation (B. D. Davis-personal communication).

$\dagger$ All growth factors required in minimal concentrations of $20 \mu \mathrm{g} . / \mathrm{ml}$.

All five ' $\mathrm{J}$ ' strains are able to ferment maltose, $\mathrm{D}$-galactose, $\mathrm{D}$-xylose, D-mannitol and L-arabinose. In addition, J 5-3, J 5-10 and J 13-4 ferment lactose but $J_{4-5}$ and $\mathbf{J}$ 6-2 are unable to ferment it. All strains produced recombinants with $\mathrm{W}-677 / \mathrm{F}^{-}$and were inferred to be $\mathrm{F}^{+}$. The presence of prototrophic recombinants from the mating of $\mathrm{J} 5-3\left(\mathrm{P}^{-} \mathrm{M}^{-}\right)$with 58-161 $\left(\mathrm{M}^{-}\right)$ on MM was taken to indicate that the methionine markers carried by these strains are non-allelic. For convenience, the $\mathrm{M}^{-}$locus of 58-161 will be designated $\mathrm{M}_{1}^{-}$, and that of $\mathrm{J} 5-3, \mathrm{M}_{2}^{-}$.

Media and recombination techniques were the same as described previously (Clowes \& Rowley, 1954).

Biochemical tests. Master plates of purified recombinant colonies, prepared as described previously (Clowes \& Rowley, 1954), were used for the testing of fermentation reactions and auxotrophic requirements by the replica plating method of Lederberg \& Lederberg (1952), all sugar fermentation tests being carried out on eosin-methylene blue medium.

\section{RESULTS}

Table 2 shows the segregation of the six sugar markers $\mathrm{Mal}_{1}, \mathrm{Lac}_{1}, \mathrm{Gal}_{5}, \mathrm{Xyl}$, Mtl and Arab among the recombinants resulting from the matings of $\mathrm{W}-677 / \mathrm{F}^{-}$ (or $\mathrm{W}-677 / \mathrm{St}^{\mathrm{B}} / \mathrm{F}^{-}$) with $\mathrm{K}-12,58-161 / \mathrm{F}^{+}$and the five ' $\mathrm{J}$ ' strains on minimal 


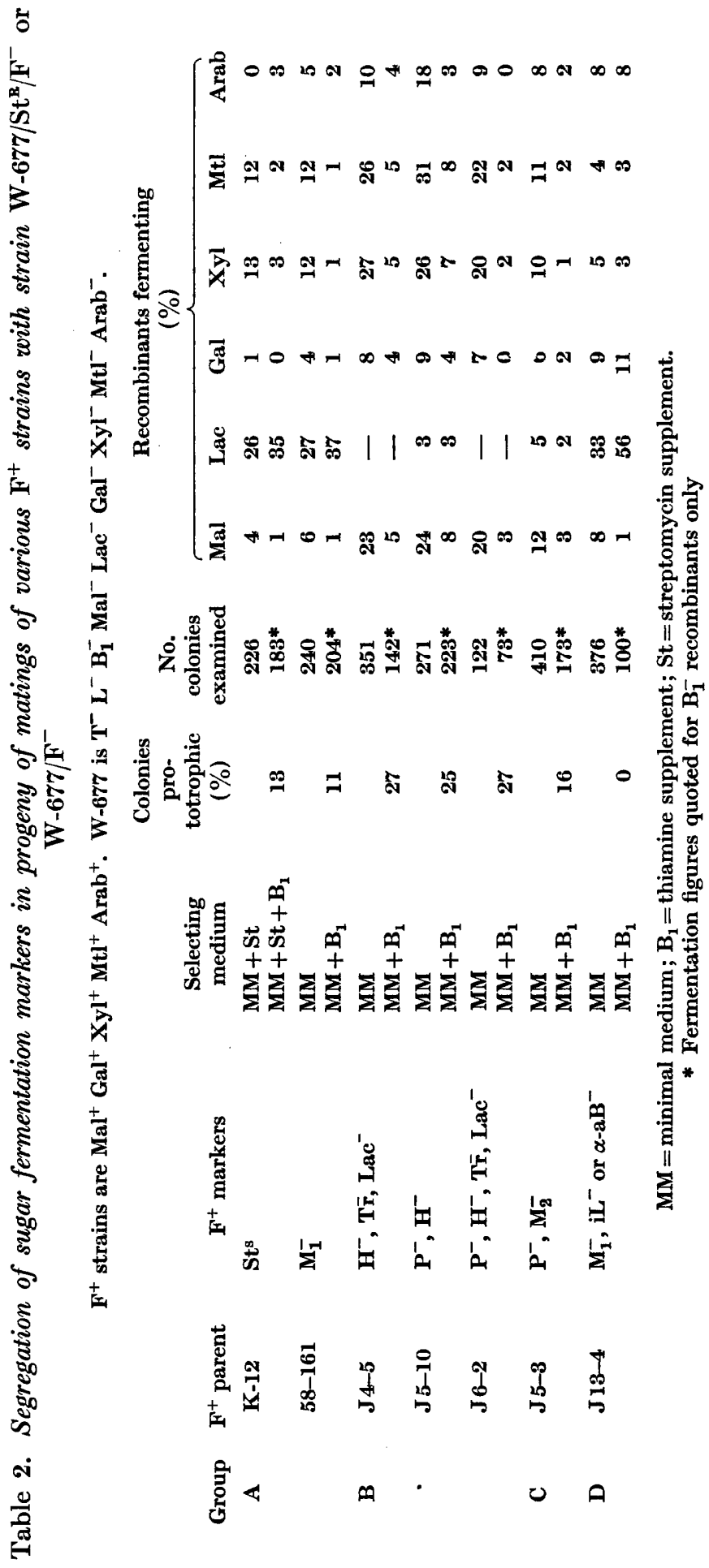




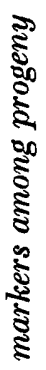

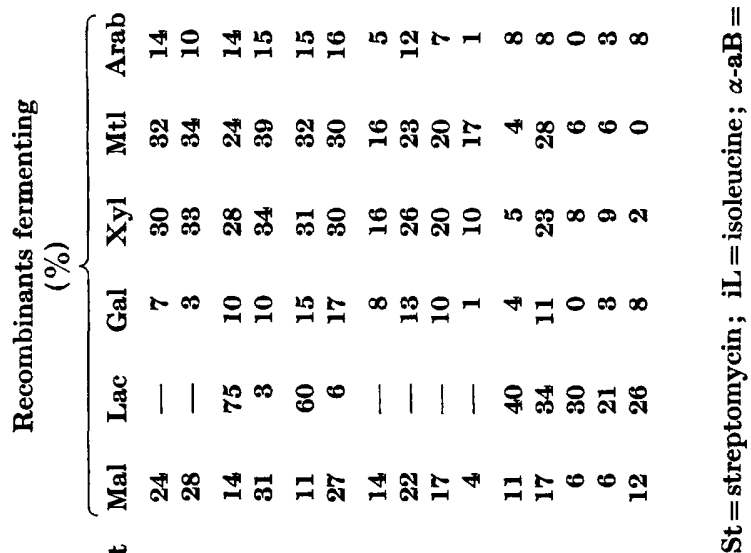

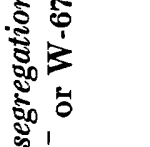

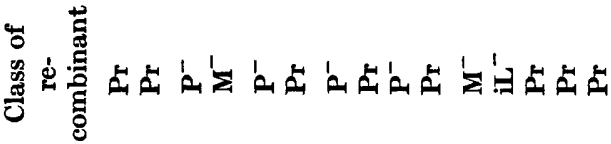
ริ

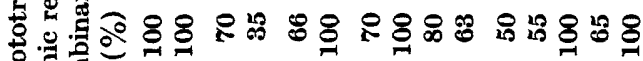

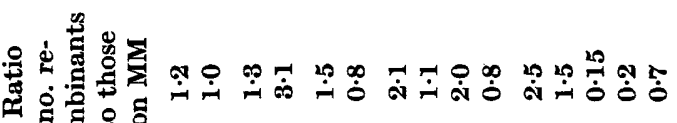


medium (MM) and minimal medium supplemented with vitamin $\mathbf{B}_{1}\left(\mathbf{M} M+\mathbf{B}_{1}\right)$. These matings may be conveniently separated into four groups of similar segregation patterns. It is apparent from these different groups that the genotype of the $\mathbf{F}^{+}$parent has a significant effect on the genotype of the recombinants, under the experimental conditions used. In order to investigate this effect more fully, certain matings were repeated and seeded on minimal media supplemented with the individual growth factors of the $\mathrm{F}^{+}$parent, in cases where this parent has more than one growth requirement. The results of such matings are summarized in Table 3 . The effect of the addition of the $\mathrm{F}^{+}$growth factors shows that the supplements methionine, isoleucine and proline affect the recombination rate, the growth requirements of the recombinants and their sugar fermentation pattern. All recombinants arising on MM supplemented with either histidine or tryptophan were capable of growth on unsupplemented MM and their sugar fermentation patterns were similar to that arising on MM alone (Table 2).

Table 4. Segregation of sugar markers from the mating

\begin{tabular}{|c|c|c|c|c|c|c|c|c|c|}
\hline \multirow{2}{*}{$\begin{array}{c}\text { Selecting } \\
\text { medium }\end{array}$} & \multirow{2}{*}{$\begin{array}{c}\text { Ratio } \\
\text { recombina- } \\
\text { tion rate } \\
\text { to that on } \\
\text { MM }\end{array}$} & \multirow{2}{*}{$\begin{array}{l}\text { Recombi- } \\
\text { nants grow- } \\
\text { ing on MM } \\
(\%)\end{array}$} & \multirow{2}{*}{$\begin{array}{l}\text { No. colonies } \\
\text { tested for } \\
\text { sugar fer- } \\
\text { mentation }\end{array}$} & \multicolumn{6}{|c|}{$\begin{array}{c}\text { Progeny not fermenting } \\
(\%)\end{array}$} \\
\hline & & & & Mal & Lac & Gal & $\mathrm{Xyl}$ & Mtl & Arab \\
\hline MM & 1 & 100 & 412 & 21 & 4 & 8 & 26 & 25 & 7 \\
\hline $\mathrm{MM}+\mathrm{B}_{1}$ & 1.9 & 55 & $130^{*}$ & 23 & $\mathbf{5}$ & 4 & 40 & 34 & 4 \\
\hline
\end{tabular}

\section{DISCUSSION}

One of the difficulties in studying the genetics of Escherichia coli $\mathrm{K}-12$ has been to account for the position of the known markers on the basis of one or more straight or branched chromosomes. The present data are discussed on the basis of a multichromosome system and then on the basis of limited transfer of fragments of a single chromosome.

Multi-chromosome hypothesis. Watson \& Hayes (1953) suggested that the present markers could be arranged in three linkage groups, characterized by the loci St-Mal, $\mathbf{M}_{1}-\mathrm{B}_{1}$ and TL-Lac 1 , and Hayes (1953b) suggested that recombination data could be interpreted on the basis of at least three discrete chromosomes. In recombination a one-way transfer of usually only one of the chromosomes of the $\mathrm{F}^{+}$parent was postulated. If this transferred chromsome carries one selected marker only, then it follows from the above hypothesis that other loci carried by this chromosome should appear in the progeny to the extent of 50-100\%, depending upon whether there is no linkage (50\%) or complete linkage $(100 \%)$ of the unselected marker in question with the selected marker. Other markers on any chromosome not carrying a selected marker should appear in the progeny at a small random rate, depending only upon the frequency with which this chromosome happens to be transferred from the $\mathrm{F}^{+}$parent in addition to that chromosome carrying the selected markers from the $\mathbf{F}^{+}$strain. 
In an example quoted by Watson \& Hayes, the cross of $\mathbf{W}-677 / \mathrm{F}^{+} \times 58$ $161 / \mathrm{F}^{-}$on $\mathrm{MM}+\mathrm{B}_{1}$ where only the chromosome carrying the $\mathrm{M}_{1}^{+}$locus is being selected, there was a transfer of $61 \% \mathrm{~B}_{1}$ and $21 \% \mathrm{Mtl}$. The loci $\mathrm{B}_{1}$ and $\mathrm{M}_{1}$ are postulated to lie on the same chromosome, and Mtl on another, yet there does not appear to be any clear-cut difference between the so-called random transfer of $\mathrm{Mtl}$ and the linked transfer of $\mathbf{B}_{1}$.

In a mating of $\mathrm{J} 5-3\left(\mathrm{P}^{-} \mathbf{M}_{2}^{-} \mathrm{B}_{1}^{+} \mathrm{T}^{+} \mathrm{L}^{+}\right)$and $\mathrm{W}-677 / \mathbf{F}^{-}\left(\mathrm{P}^{+} \mathbf{M}_{2}^{+} \mathrm{B}_{1}^{-} \mathbf{T}^{-} \mathbf{L}^{-}\right)$on $M M+M+B_{1}$ we found that of 82 recombinants examined 53 were $M_{2}^{+} B_{1}^{-}, 22$ were $M_{2}^{-} B_{1}^{+}, 6$ were $M_{2}^{+} B_{1}^{+}$and 1 was $M_{2}^{-} B_{1}^{-}$. This shows that the $M_{2}$ locus is also linked to $\mathrm{B}_{1}$ and by the Watson \& Hayes hypothesis it is situated on the same chromosome as both $\mathbf{M}_{1}$ and $\mathbf{B}_{1}$.

A consideration of some of the present data shows that the proposed random transfer of some markers is considerably affected by the transfer of a supposedly non-homologous chromosome. For example, in the cross J5-3 $\times \mathrm{W}-677 / \mathrm{F}^{-}$ on MM (Table 2) the chromosomes carrying the selected markers $\left(\mathrm{B}_{1}^{+}, \mathrm{T}^{+}\right.$ and $\mathrm{L}^{+}$) would need to be contributed by the $\mathrm{F}^{+}$parent to all viable recombinants. However, since the $\mathrm{F}^{+}$chromosome carrying $\mathrm{B}_{1}^{+}$also carries the $\mathrm{M}_{2}^{-}$marker of the $\mathrm{F}^{+}$parent, crossover in this chromosome is necessary to secure a viable recombinant, which must carry the loci $\mathbf{M}_{2}^{+}$and $\mathbf{B}_{1}^{+}$, i.e. the locus $\mathbf{M}_{2}^{-}$is 'contra-selected'. On $M M+M$, the same chromosomes are transferred from the $\mathrm{F}^{+}$parent, but the class of progeny which carry the $\mathbf{M}_{2}^{-}$locus is now viable. If this class is examined ( $\mathbf{M}_{2}^{-}$colonies, Table 3 ) the percentage transfer of the loci $\mathrm{Mal}, \mathrm{Xyl}$ and $\mathrm{Mtl}$ is seen to differ significantly from that of the $\mathrm{M}_{2}^{+}$class of recombinants (see Table 2). In this mating, the transfer of 10-12\% of Mal, Mtl and Xyl on MM (Table 2) would be supposed random on Watson \& Hayes's interpretation. However, by transferring an additional piece of another $\mathrm{F}^{+}$chromosome (that containing the $\mathbf{M}_{2}^{-}$locus) the simultaneous transfer of these sugars is increased to $31-39 \%$. The inference must be that the transfer of these sugar markers is not random, and furthermore that in some way they are linked with $\mathbf{M}_{2}$ and thus to $\mathbf{B}_{\mathbf{1}}$.

It is evident on consideration of the recombination data available (Lederberg, 1947; Lederberg, Lederberg, Zinder \& Lively, 1951; Cavalli et al. 1953; Hayes, 1953 $a$; Rothfels, 1952) that the known markers tend to lie in the linkage groups as postulated by Watson \& Hayes (1953), but that these form discrete chromosomes is by no means certain as the present data show.

Limited transfer of fragments of a single chromosome. Previous work, as well as the above result, can be interpreted on the basis of a single linear chromosome which fragments at random during recombination, a possibility considered by Watson \& Hayes (1953). The three groups of markers must then be considered to occupy small separated segments of this single chromosome. It is necessary to visualize fragmentation of this chromosome at some time during recombination since not all markers are transferred to an extent of 50-100\% even when the $\mathbf{F}$ polarity is reversed (e.g. in the case of Gal and Arab in the two crosses of 58-161 and W-677; Tables 2 and 4). The appearance of any unselected marker of the $\mathrm{F}^{+}$parent in the recombinants must depend on the frequency of its incorporation on the same chromosomal fragment as 
a selected marker from the $\mathrm{F}^{+}$parent, this transfer being proportional to the proximity of the two loci. This implies that any transfer, however small, is due to some degree of linkage.

On this concept of limited transfer, the experimental evidence may be interpreted as follows. In the cross $\mathrm{J} \mathrm{5-3}\left(\mathrm{P}^{-} \mathrm{M}_{2}^{-}\right) \times \mathrm{W}-677 / \mathrm{F}^{-}$on MM (Table 2) the loci $\mathrm{T}^{+}, \mathrm{L}^{+}$and $\mathrm{B}_{1}^{+}$are selected from $\mathrm{J} \mathrm{5-3}$ but the $\mathbf{M}_{2}^{-}$locus is contraselected and the transfer of sugar markers Mal, $\mathrm{Xyl}$ and $\mathrm{Mtl}$ is small (Mal $12 \%$, Xyl $10 \%$, Mtl $11 \%$ ). On MM + M however (Table 3), where the $\mathbf{M}_{2}^{-}$locus can be carried by viable recombinants, an increased proportion of these latter progeny possess the sugar markers (Mal $31 \%$, Xyl 34 \%, Mtl 39\%), the increased transfer being presumably due to their linkage with $\mathbf{M}_{2}$. The similarity in the distribution of these sugar markers (Table 2) among progeny from matings on MM of group ' $B$ ', where all $\mathrm{F}^{+}$parents carry the $\mathbf{M}_{2}^{+}$allele, and those of $\mathbf{J}$ 5-3 on $\mathbf{M M}+M$ supports the explanation that the differences on $M M$ are due to contra-selection of the $\mathbf{M}_{2}^{-}$locus. The transfer of the markers Mal, Xyl and Mtl are of a similar order in the crosses both of $58-161 / \mathrm{F}^{+}$and $\mathrm{J} \mathrm{5-3}$ with $\mathrm{W}-677 / \mathrm{F}^{-}$ on MM (Table 2), which confirms the proximity of the $M_{1}$ and $M_{2}$ loci. It seems likely that contra-selection for either $\mathbf{M}_{1}^{-}$or $\mathbf{M}_{2}^{-}$is the reason for the lower transfer in both these crosses compared with the analogous results within group ' $B$ '.

That strain K-12 also resembles strain 58-161 in this respect could be attributed to the contra-selection of the $\mathrm{St}^{\mathrm{S}}$ locus which has also been shown to be linked to Mal, $\mathrm{Xyl}$ and $\mathrm{Mtl}$ by previous workers (Cavalli et al. 1953). Further evidence to support this suggestion can be got from consideration of the cross of $\mathrm{J} 6-2 \times \mathrm{W}-677 / \mathrm{St}^{\mathrm{R}} / \mathrm{F}^{-}$(Table 3). On MM the progeny from this mating resembles that of other group ' $B$ ' strains, but when contra-selection for the $\mathrm{St}^{\mathrm{B}}$ locus is applied, by selecting on $\mathrm{MM}+\mathrm{St}+\mathrm{P}+\mathrm{H}+\mathrm{Tr}$, the transfer of markers is reduced, and is similar to that observed in the cross involving $\mathrm{K}-12$ on $\mathrm{MM}+\mathrm{St}$.

The differences in $\mathrm{Lac}^{+}$transfer between crosses involving either $\mathbf{J}$ 5-3 or J 5-10 and those in which either 58-161 or K-12 is the $\mathrm{F}^{+}$parent may also be explained by the effects of contra-selection, in this case of the $\mathrm{P}^{-}$locus. In the mating of J 5-10 with W-677/ $\mathrm{F}^{-}$on $\mathrm{MM} \times \mathrm{P}$ (Table 3), there is a larger transfer of $\mathrm{Lac}^{+}$among the $\mathrm{P}^{-}$recombinants $(60 \%)$ than among the $\mathrm{P}^{+}$recombinants $(6 \%)$. This suggests $\mathbf{P}$ is closely linked with Lac and that when $\mathbf{P}^{-}$is contraselected, as in J 5-3 or J 5-10 $\times \mathrm{W}-677 / \mathrm{F}^{-}$on MM, a reduced transfer of $\mathrm{Lac}^{+}$ to the recombinants results.

The matings of $\mathrm{J} 13-4^{-\mathrm{iL}^{-}}$or $\left.\alpha-\mathrm{aB}^{-}, \mathrm{M}_{1}^{-}\right)$are more complex and not entirely explicable. The main distinctions in the progeny from this strain are the very small transfer of the markers $\mathrm{Xyl}$ and $\mathrm{Mtl}$ on MM which is less than from strains of group $\mathbf{A}$, and the lack of variation in the transfer of these markers on supplementing with $\mathbf{M}$. This would be explained by a close linkage of iL to Xyl and $\mathrm{Mtl}$ and the location of this marker between $\mathrm{M}_{1}$ and the Xyl-Mtl pair. In several recombinations selected on $\mathrm{MM}+\mathrm{iL}$, no iL $\mathrm{iL}^{-}$progeny could be detected. However, in other recombinations $\mathrm{iL}^{-}$recombinants were detected but the clones were always much smaller than those of any other class of recombinants. 
The distribution of sugar markers among these $\mathrm{iL}^{-}$recombinants shown in Table 3 shows an increase of transfer of the markers Mal, Mtl and Xyl in proportions similar to that among recombinants where the $\mathbf{M}_{1}^{-}$locus is not contra-selected, which would be expected were the iL locus situated between the $\mathbf{M}_{1}$ locus and the loci Mal, Xyl and Mtl. An attempt was made to investigate the linkage of $M_{1}$ and iL by seeding the cross $\mathrm{J} 13-4 \times \mathrm{W}-677 / \mathrm{St}^{\mathrm{R}} / \mathrm{F}^{-}$on $\mathrm{MM}+\mathrm{St}+\mathrm{iL}+\mathrm{M}$. On this medium all recombinants fell into the two classes $\mathrm{St}^{\mathrm{R}} \mathrm{iL}^{+} \mathrm{M}_{1}^{+}$and $\mathrm{St}^{\mathrm{B}} \mathrm{iL}^{+} \mathrm{M}_{1}^{-}$and this lack of $\mathrm{iL}^{-}$recombinants was confirmed by the fact that recombinants arising on $\mathrm{MM}+\mathrm{St}+\mathrm{iL}$ were all prototrophic. It was thought that this was due to the closer linkage of St and iL which would prevent their separation. No effects on recombination rate, growth requirements and sugar patterns of the progeny of the cross $\mathrm{J} 13-4 \times \mathrm{W}-677 / \mathrm{F}^{-}$were found by supplementing with $\alpha$-aminobutyric acid. However, the alternative growth requirement of isoleucine or $\alpha$-aminobutyric acid of this auxotroph makes interpretation of its mating difficult.

It should be emphasized therefore that the division of the $\mathrm{F}^{+}$strains used in this study into the four groups in Table 2 does not imply any fundamental difference in the mechanism of genetic transfer among these strains. The differences in the distribution of the various markers among their recombinants probably arise as a result of contra-selection of $\mathrm{F}^{+}$markers imposed by the selecting medium. If all contra-selection were removed it is likely that the transfer of unselected markers would be comparable in all crosses and would reflect only the various linkages of these markers to $\mathrm{T}^{+}, \mathrm{L}^{+}$and $\mathrm{B}_{1}^{+}$, the common selecting markers in all crosses.

\section{Construction of a linkage map}

On the basis of limited transfer, the data presented and that of other workers may be interpreted to construct a linkage map of the K-12 chromosome as follows.

In all the matings involving $W-677 / F^{-}$on $B_{1}$ media (Table 2 ), the $B_{1}^{+}$recombinants form $c .20 \%$ of the progeny. We may thus infer that (TL) and $\mathrm{B}_{1}$ are linked. Of the other quoted markers, selection for TL brings over only a significant amount of Lac, as shown by the crosses of group ' $A$ ' on $\mathbf{B}_{1}$ media, and supports the findings of Watson \& Hayes (1953). The introduction of selection for $\mathrm{B}_{1}$ on $\mathrm{MM}$ reduces the transfer of Lac from $c .36$ to $c .26 \%$. This reduction appears to be significant $\left(\chi^{2}=7 \cdot 3\right)$ and suggests that $\operatorname{Lac}_{1}$ and $B_{1}$ lie on opposite sides of TL.

The large reduction in the transfer of $\mathrm{Xyl}$ and $\mathrm{Mtl}$ in all crosses on eliminating selection for $B_{1}$ (Table 2 ) implies the linkage of these sugar markers with $B_{1}$ and not with TL, although the relative positions of the two sugar markers cannot be fixed unequivocally, and suggests the order

$$
\text { (Mtl-Xyl) }-B_{1}-\text { TL }- \text { Lac }_{1} \text {. }
$$

That $\mathbf{M}_{1}$ and $\mathbf{B}_{1}$ are linked has been shown by many other workers (Hayes, 1953a; Cavalli et al. 1953; Watson \& Hayes, 1953) and this is supported by the appearance of $c .50 \%$ of the one marker when the other is selected (Tables 3 
and 4). The relative positions of $M_{1}$ and $B_{1}$ is suggested by consideration of the transfer of $\mathbf{X y l}$ and $\mathbf{M t l}$ when either $\mathbf{M}_{1}$ or $\mathbf{B}_{1}$ is selected. If we suppose $\mathbf{M}_{1}$ to be situated to the right of $B_{1}$; in the cross $W-677 / F^{+} \times 58-161 / F^{-}$we would expect on $M M$ where the $M_{1}$ locus only is selected that there would be little transfer of $\mathrm{Xyl}$ and $\mathrm{Mtl}$ but that on $\mathrm{B}_{1}$ medium a larger transfer would result. If $M_{1}$ were situated between $B_{1}$ and $M t l+X y l$, however, the reverse effects would be expected, and the transfer on MM should be little affected on supplementing with $\mathrm{B}_{1}$. The data (Table 4) show transfers of $26 \% \mathrm{Xyl}, 25 \%$ Mtl on MM and $40 \%$ Xyl, 34\% Mtl on MM $+B_{1}$. The figures for Mtl do not indicate any significant increase on supplementing with $B_{1}\left(\chi^{2}=3 \cdot 85\right)$ but those of $\mathrm{Xyl}$ suggest that the variation is not random $\left(\chi^{2}=8 \cdot 5\right)$. These results are difficult to reconcile with either alternative. However, the fact that the transfer of only one of these closely linked markers seems to be increased on selecting for $B_{1}$, and that when $M$ only is transferred there is still a large amount of transfer of both markers throws doubt on the location of $B_{1}$ to the right of M. Similarly, in the cross J 5-3 $\times$ W-677/ $/ \mathbf{F}^{-}$, the situation of $\mathbf{M}_{2}$ to the right of $\mathbf{B}_{1}$ would allow a significant transfer of these sugar markers on $\mathrm{MM}$ and the transfer should be little affected on supplementing with $\mathbf{M}$. If $\mathbf{M}_{2}$ were to the left of $B_{1}$, the transfer on MM should be small and greatly increased on $M M+M$. The results shown in Tables 2 and 3 suggest that selection for $M_{2}$ has a significant effect on the transfer of either Xyl $\left(\chi^{2}=36\right)$ or $\operatorname{Mtl}\left(\chi^{2}=44\right)$. The location of $\mathbf{M}_{2}$ to the left of $B_{1}$ would appear the only satisfactory arrangement. It should be pointed out however that as well as the discrepancy for $\mathrm{Xyl}$ transfer in the first mating noted above, the fact that there is a residual transfer of $10 \% \mathrm{Xyl}$ and $11 \% \mathrm{Mtl}$ on selection for $\mathrm{B}_{1}$ and contra-selection for $M_{1}$ or $M_{2}$ would require an unusually high degree of double crossover. The unequivocal location of $M_{2}$ to the left of $B_{1}$, and the fact that contra-selection of either of the $M_{2}$ or $M_{1}$ loci in the presence of selection for $B_{1}$ as in the crosses of either J 5-3 and 58-161 with $\mathrm{W}-677 / \mathrm{F}^{-}$on MM (Table 2) gives similar transfers of $\mathrm{Xyl}$ and $\mathrm{Mtl}$ suggest that the most probable location of both $\mathrm{M}_{1}$ and $\mathbf{M}_{2}$ are to the left of $\mathbf{B}_{1}$.

Tables 3 and 4 show that when $M_{1}$ is selected or when $B_{1}$ is selected with no contra-selection for $\mathbf{M}_{2}$, a small transfer of both $\mathrm{Gal}$ and Arab is effected. This suggests that these fermentation loci which have been shown to be closely linked with the locus for resistance to norleucine inhibition, $\mathrm{Nl}$ (Clowes \& Rowley, 1954) are linked to $M_{1}$ and $M_{2}$ rather than $B_{1}$ or $T L$ and implies the arrangement:

$$
\text { (Nl-Gal } \left.{ }_{5}-\text { Arab)-(Xyl-Mtl)-( } \mathbf{M}_{1}-\mathbf{M}_{2}-\right)-\mathbf{B}_{1}-\mathbf{T L}-\mathbf{L a c}_{1} \text {. }
$$

The $\mathrm{Mal}_{1}$ locus is seen to be linked to $\mathrm{M}_{1}$ from Table 4. Its percentage transfer and the results of Cavalli et al. (1953) suggest it is linked to $B_{1}$ less than Xyl. However, in matings where $B_{1}$ is transferred, the application of contra-selection for $M_{2}$ would be expected to reduce to the greatest amount those markers nearest to $\mathbf{M}_{2}$. The results, shown in Table $\mathbf{3}$ on contra-selecting for $\mathbf{M}_{2}$ in the cross of $\mathrm{J} 5-3$, give a reduction in transfer of Mal 31 to $12 \%$, Xyl 34 to $10 \%$ and Mtl 39 to $11 \%$ and do not seem to suggest any difference in the degree of linkage of either $\mathrm{Mal}_{1}, \mathrm{Xyl}$ or $\mathrm{Mtl}$ with $\mathbf{M}_{2}$. The relative position of $\mathbf{M a l}_{1}$ with respect to Xyl 


\section{Linkage effects in recombination of $\mathrm{E}$. coli $K-12$}

and $\mathrm{Mtl}$ cannot therefore be postulated exactly. The linkage St-Mal $\mathrm{I}_{\mathbf{1}}$ has been shown by many workers. The decrease in transfer of $\mathrm{St}$ in an analogous manner to that of Mal, $\mathrm{Xyl}$ and $\mathrm{Mtl}$ when $\mathrm{M}_{1}$ is contra-selected has been noted in a previous paper (Clowes \& Rowley, 1954) where in the cross $\mathbf{J 5}-\mathbf{1 0} / \mathbf{S t}^{\mathrm{B}} \times$ $\mathrm{W}-677 / \mathrm{F}^{-}$on $\mathrm{MM}, 27 \%$ of the recombinants were $\mathrm{St}^{\mathrm{B}}$ as compared with a transfer of $10 \%$ in the parallel $58-161 / \mathrm{St}^{\mathrm{R}} / \mathrm{F}^{+}$cross. The linkage between St and Mal and Xyl, quoted by Cavalli et al. (1953) would suggest the inclusion of these markers in the order:

$$
\left(\mathrm{Nl}-\mathrm{Gal}_{5}-\mathrm{Arab}\right)-\left(\mathrm{St}-\mathrm{Mal}_{1}\right)-(\mathrm{Xyl}-\mathrm{Mtl})-\left(\mathrm{M}_{\mathbf{1}}-\mathbf{M}_{2}\right)-\mathrm{B}_{1}-\mathrm{TL}-\mathrm{Lac}_{1} \text {. }
$$

In the cross of $\mathrm{K}-12 \times \mathrm{W}-677 / \mathrm{St}^{\mathrm{R}} / \mathrm{F}^{-}$on $\mathrm{MM}+\mathrm{St}$, the similar degree of transfer of Mal, Xyl and Mtl would be explicable by the linkage of St to these markers to the same extent as $\mathbf{M}_{1}$, together with contra-selection of the $\mathbf{S t}^{s}$ locus. This is substantiated in the cross of J 6-2 (Table 3) where contra-selection for the $\mathrm{St}^{s}$ locus causes a reduction in transfer of these sugar markers to values similar to the K-12 cross.

The removal of contra-selection for proline in the crosses of J 5-10 (Table 3) allows a greater transfer of Lac, from which linkage of these two loci is inferred; this would explain the small degree of transfer of Lac in crosses involving $\mathbf{P}^{-} \mathbf{F}^{+}$strains on $\mathbf{M M}$. The data are compatible with the location of $\mathbf{P}$ between TL and $\mathrm{Lac}_{1}$, since imposing contra-selection for $\mathrm{P}$ on the selection for TL reduces the transfer of Lac from $c .24$ to $3 \%$.

The results of the crosses involving $\mathrm{J} 13-4$ can be interpreted if the locus iL is between the $\mathbf{M}_{1}-\mathbf{M}_{2}$ and the Xyl-Mtl markers. However, in view of the alternative growth requirement of this auxotroph (M-iL or $\alpha-\mathrm{aB}$ ), this result cannot be more than tentative.

From the above considerations, it seems likely that the investigated markers lie in the order:

$$
\text { (Nl-Gal }- \text { Arab)-(St-Mal })-\left(\text { Xyl-Mtl)-iL-( } \mathbf{M}_{1}-\mathbf{M}_{2}\right)-\mathrm{B}_{1}-\mathrm{TL}-\mathrm{P}-\mathrm{Lac}_{\mathbf{1}} \text {. }
$$

The brackets imply uncertainty as to the relative positions of the markers enclosed.

We would like to thank both Dr E. M. Lederberg and Dr L. L. Cavalli-Sforza for information on allelism in W-677 and W-945; and Dr B. D. Davis for the generous gift of the ' $J$ ' strains. We are grateful to Dr W. Hayes and Dr B. A. D. Stocker for helpful discussion and suggestions and to Mr R. Borghi for technical assistance.

\section{REFERENCES}

Cavalit, L. L., Lederberg, J. \& Lederberg, E. M. (1953). An infective factor controlling sex compatibility in Bacterium coli. J. gen. Microbiol. 8, 89.

Clowes, R. C. \& Rowlex, D. (1954). Genetic investigation of the inhibition by DL-norleucine of the K-12 strain of Escherichia coli. J. gen. Microbiol. 11, 27.

Davis, B. D. \& Mingioli, E. S. (1950). Mutants of Escherichia coli requiring methionine or vitamin B $12 . J$. Bact. $60,17$.

HaYes, W. (1952). Recombination in Bact. coli K-12: uni-directional transfer of genetic material. Nature, Lond. 169, 118. 
HaYes, W. (1953a). Observations on a transmissible agent determining sexual differentiation in Bacterium coli. J. gen. Microbiol. 8, 72.

HAYES, W. (1953b). The mechanism of genetic recombination in Escherichia coli. Cold Spr. Harb. Symp. quant. Biol. 18, 75.

LEDERBERG, J. (1947). Gene recombination and linked segregation in Escherichia coli. Genetics, 32, 178.

Lederberg, J. \& LeDerberg, E. M. (1952). Replica plating and indirect selection of bacterial mutants. J. Bact. 63, 399.

Lederberg, J., Lederberg, E. M., Zinder, N. D. \& Lively, E. R. (1951). Recombination analysis of bacterial heredity. Cold Spr. Harb. Symp. quant. Biol. 16, 413.

RothFELS, K. H. (1952). Gene linearity and negative interference in crosses of Escherichia coli. Genetics, 37, 297.

Watson, J. D. \& Hayes, W. (1953). Genetic exchange in Escherichia coli K-12: evidence for three linkage groups. Proc. nat. Acad. Sci., Wash. 39, 416.

(Received 1 May 1954) 